\title{
INVESTIGATION OF ENERGY LITERACY, PRACTICES OF SAVING AND RATIONAL USE OF ELECTRICITY IN STUDENTS OF FIFTH GRADE OF PRIMARY SCHOOLS
}

\author{
Dimitrios Poimenidis ${ }^{1 *}$, Vasileios Papavasileiou ${ }^{2}$ \\ 1Dr, University of the Aegean, Greece, poimenidis@aegean.gr \\ ${ }^{2}$ Assoc. Prof. Dr., University of the Aegean, Greece, vpapavasileiou@rhodes.aegean.gr \\ ${ }^{*}$ Corresponding Author
}

\begin{abstract}
The use of energy is one of the most important anthropogenic environmental issues of our century, as from its production, disposal and use there are many negative effects on the biotic and abiotic elements of the ecosphere. Reducing the environmental impact of the use of matter and energy is a key educational issue. Students are the future adult citizens, who will make decisions for themselves and their fellow human beings. For these key reasons, Primary Education plays an important role in raising environmental awareness and shaping the behaviours of critical children, who need to be oriented towards a sustainable future through their energy literacy, in the context of sustainability education. The purpose of this study is to capture and highlight the basic knowledge, perceptions and daily practical functions of children in the use of direct-visible or otherwise functional energy, which is perceived in children relatively easily, directly and quickly and then their correlation of the findings on the effectiveness of children's taught energy literacy in their school education. The sample of the study consisted of 132 students of 5th grade of 3 Primary Schools in the city of Rhodes. The data collection was done using a structured and anonymous questionnaire and the questions were mainly closed type. Issues of anonymity and ethics were observed. Data were analyzed using the statistical program SPSS 25 . The results of the study reveal lack of knowledge and misunderstandings in matters of forms and sources of energy, in the view of oil by several children wrongly as a Renewable Energy Source, in the knowledge of the unit of measurement of electricity, in the type of main energy sources in Greece and Solar energy as a form applied in Greece, a country with more than 300 days of sunshine per year. The concepts of energy efficiency and climate change also indicate the need for retraining, while carbon dioxide emissions are wrongly linked to the use of solar energy. Regarding the individual practices of energy austerity, saving and rational use of energy, they seem to be at a fairly satisfactory level compared to knowledge. In particular, children state that they reduce electricity as they turn off most electrical appliances after use, they turn off the lights in places they do not use while the use of energy-saving lamps seems to prevail. In cases where heating is needed due to cold weather, children state that they prefer to wear more clothes than to increase the heating degrees of the thermostat, while, when ventilating the premises, they turn off the heating (or cooling) sources, contributing significantly to the energy and environmental economy. Undoubtedly, there is still, albeit to a limited extent, the possibility of further improving them for a small number of students. The results briefly show significant misunderstandings in matters of knowledge and deficient energy behaviour regarding the use and reduction of energy by a small number of children. The need arises for the retraining of children in an active experiential way through welldesigned Education and Sustainability Education programs, as the development of ecological awareness is an important educational goal for the formation of energetically literate students.
\end{abstract}

Keywords: Energy literacy, energy saving, use of materials, knowledge, opinions 


\section{INTRODUCTION}

Energy is one of the most important issues of the 21 st century and one of the biggest challenges is global warming (Lichtenwoehrer et al., 2019). Energy consumption has brought economic growth. It is also a central issue of the economy, as it is related to investments and jobs that enhance the economic development of countries (Tong et al., 2020). Dependence on conventional fuels, high consumption and their use has created modern bases of development in industrial, economic and social level and continues to support them, while it seems that the production and consumption of fossil fuels will continue to increase. (Provornaya et al., 2020). Ensuring these is still a field of competition, claims and counter-claims to this day, as a period is passing which is occupied by issues related to their provision, as they are still associated with the socio-economic development of a state (IES, 2015). The search and provision of these create a variety of environmental, developmental and geopolitical issues (Lekka \& Kyriazes, 2013). Their use seems to be significantly linked to a non-sustainable development model that exacerbates abiotic factors, which are essential for the living of all living things (European Environment Agency, 2019). Therefore, addressing the issue of energy consumption, greenhouse gas emissions and maintaining a stable economy would significantly improve the present in favour of a truly sustainable future, as it would reduce carbon dioxide $\left(\mathrm{CO}_{2}\right)$ emissions and improve energy efficiency (Pao \& Chen, 2019).

According to recent data from the European Environment Agency (EEA, 2019), the average European citizen consumes 27 Megawatts per hour (MWh) and this concerns the residential, industrial and transport sectors. This magnitude varies considerably from country to country, and the same is true for the relative $\mathrm{CO}_{2}$ emissions, which depend directly on the penetration rate of Renewable Energy Sources (RES) and existing nuclear energy in several European countries. In Greece, during the year 2019, the total electricity produced by all forms in the production system amounted to 36167.504 MWh (Independent Power Transmission Operator, 2019, p. 36), not counting network losses. Transport, the sector with the fastestgrowing energy consumption since 1990, is now at the top of energy consumption. Fossil fuels still dominate the fuel mix: About $77 \%$ of the average European needs energy, oil, gas and coal. As a result, the concentrations of carbon dioxide $\left(\mathrm{CO}_{2}\right)$ in the atmosphere increase, resulting in climate change and the simultaneous increase of the global average temperature (EEA, 2019).

Contemporary environmental issues are intertwined with the globalization of development and directly related to their globalization, as issues beyond the local environment (Amodu, 2019). They exist as a small or larger part, different for each country and a problem of local, regional and global dimension. However, from the globalization of environmental issues and problems, man must be led to the "need to globalize responsibility and environmental protection" (Tang et al., 2020; Pereira, 2015).

The development sectors of modern society seem to be obliged to make solutions for the widespread adoption of RES technologies that contribute significantly to sustainable development (Karatayev \& Clarke, 2016; Van der Horst et al., 2016) with simultaneous and gradual decoupling of dependence on nonrenewable energy resources (Van der Horst et al., 2016). The use of these resources has been shown to create a host of environmental issues (Chen et al., 2013). The development of simple energy technologies for daily living and human activities across the spectrum, combined with the reduction of energy use (Moriarty \& Honnery, 2019) and the increase of energy efficiency (UNECE, 2019), are the second important pole of development of a model of accelerating progress towards sustainable development. Technologies for these purposes exist and are available at relatively low cost. However, energy efficiency depends, in addition to the availability of cheap technologies or policy interventions, to a large extent on individual behaviour, as, for example, the purchase of efficient appliances is not adopted or used in the most efficient way (Boogen et al., 2016).

\subsection{The Energy Dimension In Formal Education}

Sustainable development, which depends on the rational use and limitation of the use of natural resources, means the existence of serious challenges but also prospects in the field of energy in general (Ingaldi \& Klimecka-Tatar, 2020). Lack of basic energy skills by citizens also seems to be an issue that needs to be addressed in detail, as energy consumption sectors cover a wide range of uses and citizens' skills, perceptions and attitudes are directly related to reducing or worsening the energy footprint (Bloom \& Fuentes, 2018). Therefore, the "economy" of energy, reflects exactly what is happening in society and schools themselves.

The interdisciplinary approach to the issue at the level of school education connects education with a differentiated framework of values, which aims at the formation of integrated citizens and not simply at the creation of "trained or intelligent workers" (Hellenic Ministry of Education, Lifelong Learning and Religions, 2003). In the case of energy literacy and energy education of children, it should focus on making the student 
energy literate (Cotton et al., 2015). Thus, the student, in addition to knowledge, will understand how energy is used daily, the social and environmental impact of overconsumption, the need to save and rational use, will be able to make decisions oriented towards simple energy choices to access energy challenges and difficulties while undertaking actions in favour of sustainability (Akitsu et al., 2017). The cognitive factor is not an end in itself to education but a "first vehicle" in the direction of children's energy literacy and active environmental citizenship.

Energy literacy programs, therefore, should increasingly focus on raising awareness for taking action to reduce energy (Brounen et al., 2013) across the spectrum of children's daily lives. The society of the future depends on the formation of the current student/citizen, through education, that is, on the type of citizen that is formed today, through the educational process. On the issue of energy, in particular, to enable it to understand:

a. The unsustainable behaviour of the average person today and the impact on both themselves and the environment from the reckless use of energy,

b. The vicious circle between the quality of life and environmental degradation (with the existing unsustainable conditions and ways of realizing the average person),

c. Its dynamics for the reduction of energy consumption, the improvement of energy efficiency and the promotion of RES by taking individual responsibility for action and

d. The interconnection of the individual, local, regional and global dimension of the issues.

Energy literacy, then, is the understanding of the nature and role of energy in everyday life, the ability to answer questions and the ability to solve problems (US Department of Energy, 2019).

In recent years, children's energy literacy programs have focused on the personal field of students in terms of reducing use and saving energy. Furthermore, it is observed that organized educational interventions for students can improve issues of energy saving and rational use in the same children and their parents (Grønhøj, 2015). Therefore, education for sustainability, in the sense of the holistic approach and the connection of the school with the local community and local issues, is an important educational necessity (Papavasileiou, 2015; Papavasileiou et al., 2017; Papavasileiou et al., 2018).

In general, children as energy consumers consume less energy compared to adults. A study in Japan (Yamaguchi et al., 2012) found that children consume less energy than adults, using between $1 / 3$ and $1 / 2$ of the total energy an adult consumes at home, at work or in its transport. Of course, this is precarious, as few studies have focused on children as the main energy consumers, while at the same time the consumer culture plays an important role (Fell \& Chiu, 2014). This discrepancy exists and children should be treated as co-consumers of energy. According to this, their energy practice during their daily life can be indirectly evaluated, as at the level of purchasing decisions and adoption of energy-efficient technologies they can, with a relatively small range of responsibilities, make corresponding purchases.

However, they can be informed and sensitized through education, use energy rationally and learn to apply energy reduction practices in their daily lives (Lefkeli et al., 2018) or to put pressure on parents and adults to the adoption of energy lean technologies market or adoption of broader energy lean approaches. Furthermore, their energy background and awareness of energy austerity and energy choices will be the key to their future energy behaviours and choices as adults, as energy-educated people are expected to take responsible action, to the best of their knowledge. and their shaped perceptions (Yeh et al., 2017).

\section{METHODOLOGY}

This study examines a variety of aspects of the daily energy practice, management and behaviour of primary school students, based on their energy literacy. The areas of research are general data on energy, heating, electricity and transportation in their daily lives.

The research was carried out on 5th-grade students of an elementary school in an urban area, after the completion of the course in the chapter "Energy" of the subject of Physics, while there were 132 random samples. The knowledge and perceptions of students, as well as the feasible successful energy reduction practices in their daily life, present the degree of success and effectiveness of teaching regarding their energy literacy and materialized energy behaviour, as an objective result of their energy education.

The study is quantitative with qualitative characteristics. The data were analysed with the statistical package SPSS Statistics 25. It was implemented through a structured and anonymous questionnaire, as this is regarded as the most appropriate methodological tool for investigating the issues under consideration (Cohen et al., 2011). It includes a total of 23 questions/statements, mainly closed-ended that contain 
individual sub-questions. Its ultimate goal is to highlight the existing energy literacy of children in this class. It also adapted to the children's language level to safely extract data on exploratory issues.

Issues of anonymity and ethics were observed. The research is a case study while the generalization of its results is treated with relative reservation.

\section{RESULTS}

The sample of the study consists of boys at a rate of $57.6 \%$ and girls $42.4 \%$, students of the 5 th grade. The results of the study are analysed in terms of their percentage of descriptive analysis and presentation.

Regarding the energy sources that are considered renewable, with options given in combinations in groups, among which there was some form of energy that was not included in RES, many students $(51.5 \%)$ answered correctly referring to RES as wind energy, solar energy, water, biomass and geothermal energy. However, several children (36.4\%) referred to nuclear energy as RES, while a few (12.1\%) incorrectly referred to oil as RES.

When asked which energy source is a fossil fuel with biogas, natural gas and nuclear energy options, the students' answers were given without any significant percentage difference or deviation but with quite incorrect answers. Thus, biogas (30.3\%), natural gas (30.3\%) and nuclear energy (39.4\%) are incorrectly mentioned as fossil fuels.

In a separate statement, which specifically concerns whether oil is a renewable or non-renewable energy source, many students $(51.5 \%)$ incorrectly refer to it as RES, while several students $(48.5 \%)$ correctly state that oil does not belong to the category of RES.

When asked about energy sources that can release carbon dioxide $\left(\mathrm{CO}_{2}\right)$ into the atmosphere, several children (42.4\%) correctly mention fossil fuels. Others (36.4\%) also incorrectly answer that solar energy releases carbon dioxide $\left(\mathrm{CO}_{2}\right)$ into the environment, while a few children $(21.2 \%)$ incorrectly answer that wind energy releases carbon dioxide $\left(\mathrm{CO}_{2}\right)$ in the atmosphere. Combined with their answers, many children $(57.6 \%)$ report that RES release carbon dioxide $\left(\mathrm{CO}_{2}\right)$ into the atmosphere. This is a serious issue of retraining students to remove this misunderstanding.

Regarding the question of whether students have received education and are aware of the issue of energy efficiency of energy sources and the effects of energy use on the issue of climate change, several students $(45.5 \%)$ state how references and didactic approaches were made during the lesson on these issues, while many students $(54.5 \%)$ maintain that no references and didactic approaches were made on this issue.

Regarding the question of what the greenhouse effect is, for several children (42.4\%) it is defined as a natural process that regulates the earth's temperature. Several children $(36.4 \%)$ also define it as the increase in global warming due to anthropogenic activities, which emit greenhouse gases. Few of them cite it as synonymous with climate change (21.2\%). In any case, many students as a whole report it as a humancentred problem by $57.6 \%$ and not an issue that arises from the environment itself or some natural process.

Children also associate the intensity of the greenhouse effect with the production of carbon dioxide $\left(\mathrm{CO}_{2}\right)$ $(48.5 \%)$ and methane $\left(\mathrm{CH}_{4}\right)(30.3 \%)$, known greenhouse gases which are responsible for the intensification of. Of course, there is a misunderstanding by children, as they report to a small extent $(21.2 \%)$ and incorrectly, that oxygen also has a positive effect on the intensification of the greenhouse effect.

Room heating, in general, is a highly energy-intensive sector, especially in winter, as in Greece the summer is particularly hot. In the scenario that states that the windows of the house are closed, the heating is on, but we are still cold, they are asked to choose from the given statements what they would do as an immediate and first thought. Many children (69.7\%) reported that they prefer to wear another layer of clothing in order to dress better to face the cold they feel aware of this possibility and the cost reduction of the energy that will be converted. The remaining pupils (30.3\%) simply stated that they would increase the intensity of the heating in their room to keep warm.

As for the practice of refreshing the air in their classroom at school, which is implemented with a short opening of the windows for health reasons, the majority of students $(75.8 \%)$ report that the heating is stopped properly for as long as the indoor air is refreshed and that brings about quite a large energy reduction. Few of them (24.2\%) report that the heating in their classrooms works without interruption during the ventilation of their classroom, causing energy waste.

The same practice of air renewal with the heating off is very much implemented in the environment of the children's home and to a greater extent compared to the school unit according to their statements (81.2\%). Few students $(18.25 \%)$ report that this energy-saving practice is not applied in general and heating 
continues to work.

The existence of heating in conditions of relative comfort is an important parameter of energy savings. An increase in temperature of 2 degrees Celsius $\left({ }^{\circ} \mathrm{C}\right)$, puts a considerable burden on energy costs. The heating in the school is mainly regulated at $20{ }^{\circ} \mathrm{C}(60.6 \%)$, while some children report $18{ }^{\circ} \mathrm{C}(21.2 \%)$, or $22{ }^{\circ} \mathrm{C}$ $(18.2 \%)$. The temperature in the house is generally lower, as the answers are evenly distributed at $18{ }^{\circ} \mathrm{C}$ $(45.5 \%)$ and $20{ }^{\circ} \mathrm{C}(45.5 \%)$, while a few children $(9.1 \%)$ report $22{ }^{\circ} \mathrm{C}$. It seems that the cost of energy is rather taken into account, since the house is more strictly observed the reduction of energy, which is paid by the parents and, obviously, in the home environment, they save more energy and money.

The assumption of individual energy restraint practices by children is the ultimate goal of environmentally conscious behaviour. The aim is to educate them in the context of sustainability education and to adopt practices of saving, reduction, rational use or non-use of energy.

As children, in general, also consume energy, it seems that they adopt a saving practice to a significant degree, as they always close the screens of devices after their use (72.7\%) or sometimes (27.3\%). No child leaves a computer or TV screen on at all times. In the case of gaming machines, however, their practices seem to differ significantly, as only $18.2 \%$ of children turn them off completely, while a few of them (21.2\%) sometimes. Most students (60.6\%) do not suspend their function, so they can play at any time.

As for the lighting of the spaces of their house, they make a significant degree of closing of the lights (78.8\%) when they leave the room or the space in which they were and the lighting operation is not necessary. Some children (12.1\%) apply this practice occasionally, while, in general, very few children (9.1\%) are indifferent to doing so and leave the lights on.

Students are very ignorant about the unit of measurement of electricity consumption since only $21.2 \%$ of children correctly report kWh as the unit of measurement, while the rest of them report a significant degree $(60.6 \%)$ incorrectly Volt or Hertz (18.2\%).

Among the energy sources used in the local system for energy production, few children (6.1\%) correctly report the exploitation of solar energy which, of course, exists in a small percentage, while many children $(60.6 \%)$ do not know the energy source locally which is oil. The remaining children (33.3\%) answer incorrectly. This means that the issue of huge oil consumption in the local system for electricity generation is not known.

As for the practice of saving energy by children, regarding the closing of the computer after its use, it seems to be implemented to a significant degree, as many children (81.8\%) turn it off immediately after its use, while few of them either leave it in standby mode $(9.1 \%)$ or just leave it running without needing it $(9.1 \%)$, wasting energy.

Regarding the use of energy-saving light bulbs, many children report that energy-saving light bulbs are used both in their school (63.6\%) and at home (57.6\%). The rest of them report that both at school (36.4\%) and home $(42.4 \%)$ they use old technology lamps, which are not environmentally friendly, as a result of which electricity is wasted. This issue should be another field of didactic approach aimed at informing the students. Of course, in this issue, there is the issue of ignorance on the part of children about whether such lamps are actually used and additional research on whether there are indeed several houses (42.4\%) that use environmentally friendly lamps.

Regarding the energy-saving behaviour, which goes back to the use of electrical appliances in an environmentally friendly way, many children report that electrical appliances turn off or unplug after use, both at school $(75.8 \%)$ and in their home $(72.7 \%)$, thus contributing significantly to energy savings. Few children report that such practices are not implemented in the school unit $(24.2 \%)$ and at home $(27.3 \%)$, indicating that there is still room for improvement in this practice.

Furthermore, the control of the energy labelling of electrical appliances as a basic condition for their purchase choice seems to be implemented considerably (57.6\%). This practice is an important parameter for measuring energy austerity and energy savings. The declared percentages would be expected to be significantly higher and this is not the case. Therefore, there is still a considerable scope (42.4\%) to enhance this dimension through an educational intervention that can lead to further energy savings in the long run.

\section{DISCUSSION AND CONCLUSIONS}

Clarifying and understanding children's behaviour regarding energy saving and rational use is something that can make a positive contribution to making appropriate policy and educational choices. The information collected from the survey with a questionnaire, highlights the existing cognitive misunderstandings, deficiencies and the need for restraint, in order to strengthen the cognitive background of students and 
strengthen their energy-saving practices, which are absolutely necessary in the context of sustainability. (Ntona et al., 2015).

In particular, the serious misunderstandings in matters of knowledge of forms and sources of energy, but also the misunderstanding that oil is considered a renewable energy source by about half of the students, shows that the cognitive factor of basic elements of energy literacy lags significantly. This demonstrates the need to change the approach and the way of teaching children and, of course, marks the re-teaching of the respective issues for the restoration of the cognitive deficit. Children's energy literacy is broadly reduced to knowledge about the production and consumption of energy, the effects of its production and use on the environment and society, but also their attitudes and values, their emotional and behavioural characteristics to get the right and appropriate decisions on the issue of energy (Martins et al., 2020).

Respectively, there are serious cognitive deficiencies in the type of units of measurement of electricity, as few children know the unit of measurement $(\mathrm{kWh})$ correctly. Also, a very serious cognitive deficit is observed in the type of basic sources used in our country for energy production. Few students cite solar energy as one of the existing forms of energy production. This is a critical feedback issue.

The production of carbon dioxide, associated with the greenhouse effect (and at the same time an issue that is often raised in the media), is little known in relation to the type of fuel that causes and aggravates the phenomenon. As might be expected, the serious issue that arises is the completely wrong connection of carbon dioxide $\left(\mathrm{CO}_{2}\right)$ production with RES and this is a matter for a feedback approach and teaching. Furthermore, children's knowledge of the natural (and man-made) effect of the greenhouse, although diffused in its manifestations, is nevertheless in the right direction. This is because there is no prior knowledge taught in school education (Rosidin \& Suyatna, 2017). The concepts of climate change and energy efficiency are also an additional issue of the need for retraining and feedback of students.

Regarding the individual practices in the fields of energy austerity, saving and rational use of energy, they seem to be at a much better and sufficiently satisfactory level compared to the aforementioned knowledge. The reports of the children present particularly positive results for the heating and cooling practices of the spaces where the children are, not only good practices for reducing energy when these spaces are ventilated but also the thermal comfort that must exist in these spaces. These findings are consistent with similar findings in students in the Philippines (Cruz, 2017). Thermal comfort should be at the limit of standard comfort so that the lesson is implemented indefinitely (when the children are at school) or at home during the remaining hours. The prevailing temperatures are appropriate and operate both at school and at home with some variation, comparatively higher in the school, in the area of thermal elementary comfort (Lefkeli et al., 2018).

In matters of saving and rational use of electricity, too, children show considerable energy sensitivity, in the sense of reducing electricity, being consumers either at school or at home. They know and generally turn off the screens of the devices they used after the activity. They turn off the light bulbs in their living spaces and their computer when they complete their tasks and activities. They appear oriented in favour of energy reduction (Yeh et al., 2017). An exception in favour of energy-consuming behaviour is the use of slot machines. Their operation and use by children differs significantly from the other electricity reduction practices they have generally adopted. This is another important issue for changing their attitudes, in favour of reducing energy, through educational intervention.

Moreover, the use of energy-saving light bulbs is well known and adopted as a practice, either at school or at home, but there is some room for strengthening the tendency to put pressure on adults to use such light bulbs by everyone. Corresponding "pressure" can be exerted by children on their parents, with the aim of purchasing, exclusively energy-efficient devices, which bear the appropriate energy label. After all, choosing a cheaper device, in the long run, proves to be more expensive, depending on its long-term daily use (NEED, 2018).

After completing the review, the electrical appliances, after their use, "unplug" or "close" the power strip, which supplies power, either at home or school, completely reducing even the smallest amounts of electricity consumed by the situation waiting. Of course, there is still ability for improvement and targeted educational intervention can maximize this practice (Lee et al., 2015, 2017).

The exploration of knowledge and practices in the daily life of children highlights, the need for retraining and strengthening the cognitive background and perceptions and practices of children, through targeted educational interventions. Also, more teaching time in educational practice (Rosidin \& Suyatna, 2017). The adoption of educational activities and the active participation of students through them in teaching are more likely to enhance the change of behaviour in favour of energy saving (Platis \& Romanowicz, 2020). An informed and energy-conscious public is more likely to participate in decision-making processes. 
Furthermore, it will be better trained to make careful and responsible decisions, choices and actions related to energy (Polikovsky et al., 2018). The students of the study, in terms of energy management practices and their knowledge of basic energy and resource issues, ranging from "moderate to satisfactory sustainable management and behaviour", if we can give a formal gradation in the concept of sustainability, general issues that need cognitive reinforcement and empowerment (Chen et al., 2015). The ultimate goal is to adopt "strong sustainable management" in the broader context of sustainability education, in favour of creating and maintaining conditions in which nature and humans "can coexist in productive harmony to support present and future generations" (EPA, 2018).

\section{REFERENCE LIST}

Akitsu, Y., Ishihara, N. K., Okumura, H. \& Yamasue, E. (2017). Investigating energy literacy and its structural model for lower secondary students in Japan. International Journal of Environmental \& Science Education, 12(5), 1067-1095.

Amodu, A. A. (2019). Globalization and Biodiversity: Issues in Environmental Justice. The International Journal of Social Sciences and Humanities Invention, 6(01), 5239-5244.

Bloom, M. \& Quebec Fuentes, S. (2019). Experiential Learning for Enhancing Environmental Literacy Regarding Energy: A Professional Development Program for Inservice Science Teachers. Journal of Mathematics, Science and Technology Education, 15(6), em1699, ISSN:1305-8223 (online).

Boogen, N., Cattaneo, C., Filippini, M. \& Obrist, A. (2018). Report on the impact of energy literacy on the level of energy efficiency. PENNY - Psychological, Social and Financial Barriers to Energy Efficiency Project, NO 723791.

Brounen, D., Kok, N. \& Quigley, M. J. (2013). Energy literacy, awareness and conservation behavior of residential households. Energy Economics, 38, 42-50.

Chen, K. L., Liu, S. Y. \& Chen, P. H. (2013). Devising a framework for energy education in Taiwan using the analytic hierarchy process. Energy Policy, 55, 396-403.

Chen, K. L., Liu, S. Y. \& Chen, P. H. (2015). Assessing multidimensional energy literacy of secondary students using contextualized assessment. International Journal of Environmental and Science Education, 10(2), 201-218.

Cohen, L., Manion, L. \& Morrison, K. R. B. (2011). Research methods in education. Oxon, UK: Routledge.

Cotton. R. E. D, Miller, W., Winter, J., Bailey, J. \& Sterling, S. (2015)."Developing students' energy literacy in higher education". International Journal of Sustainability in Higher Education, 16(4), 456-473.

Cruz, J. P. (2017). Students' Environmental Awareness and Practices: Basis for Development of Advocacy Program. International Journal for Educational Studies, 9, 29-40.

Environmental Protection Agency (EPA). (2018). What is sustainability? Washington, DC: EPA. Retrieved from https://www.epa.gov/sustainability/learn-aboutsustainability\#what

European Environment Agency (EEA). (2019). Energy. Accessed 8-12-2019 from https://www.eea.europa.eu/el/themes/energy/intro, Last modified 04 Dec 2019.

Fell, J. M. \& Chiu, F. L. (2014). Children, parents and home energy use: Exploring motivations and limits to energy demand reduction. Energy Policy, 65, 351-358.

Grønhøj, A. (2015), Consumer behaviours: Teaching children to save energy. Nature Energy, 1, Article number 16108.

Hellenic Ministry of Education, Lifelong Learning and Religions. (2003). A Cross Thematic Curriculum Framework. General Part. issue B, nr 303/13-03-03 and issue B, $n r$ 304/13-03-03. Available at http://www.pischools.gr/programs/depps/index eng.php

Independent Power Transmission Operator. (2019). Monthly Energy Reports - November 2019. Available at https://www.admie.gr/agora/enimerotika-deltia/miniaia-deltia-energeias

Ingaldi, M. \& Klimecka-Tatar, D. (2020). People's Attitude to Energy from Hydrogen-From the Point of View of Modern Energy Technologies and Social Responsibility. Energies, 13, 6495. 
International Energy Security (IES). (2015). International Energy Security: Common Concept for Energy Producing, Consuming and Transit Countries. Energy Charter Secretariat (ECS). ISBN 978-905948054-4.

Karatayev, M. \& Clarke, M. L. (2016). A review of current energy systems and green energy potential in Kazakhstan. Renewable. Sustainable Energy Reviews, 55, 491-504.

Lee, L. S., Chang, L. T., Lai, C. C., Guu, Y. H. \& Lin, K. Y. (2017). Energy literacy of vocational students in Taiwan. Environmental Education Research, 23(6), 855-873.

Lee, L. S., Lee, Y. F., Altschuld, J. W., \& Pan, Y. J. (2015). Energy literacy: Evaluating knowledge, affect, and behavior of students in Taiwan. Energy Policy, 76, 98-106.

Lefkeli, S., Manolas, E., loannou, K. \& Tsantopoulos, G. (2018). Socio-Cultural Impact of Energy Saving: Studying the Behaviour of Elementary School Students in Greece. Sustainability, 10, 737.

Lekka, A. \& Kyriazes, N. (2013). Energy and War in the 21st Century. Evolutionary and Institutional Economics Review, 10, 197-215.

Lichtenwoehrer, P., Erker, S., Zach, F. \& Stoeglehner, G. (2019). Future compatibility of district heating in urban areas-a case study analysis in the context of integrated spatial and energy planning. Energy, Sustainability and Society, 9 (12).

Martins, A., Madaleno, M. \& Dias, F. M. (2020). Energy literacy: What is out there to know?. Energy Reports, 6(1), 454-459, ISSN 2352-4847.

Moriarty, P. \& Honnery, D. (2019). Energy Eficiency or Conservation for Mitigating Climate Change? Energies, 12, 3543.

NEED. (2018). Intermediate Energy Infobook. The NEED Project. Accessed 18.1.2021 from https://www.need.org/Files/curriculum/infobook/Efficiencyl.pdf

Ntona, E., Arabatzis, G. \& Kyriakopoulos, G. L. (2015). Energy saving: Views and attitudes of students in secondary education. Renewable and Sustainable Energy Reviews, 46, 1-15.

Pao, T-H. \& Chen, C-C. (2019). Decoupling strategies: $\mathrm{CO}_{2}$ emissions, energy resources, and economic growth in the Group of Twenty. Journal of Cleaner Production, 206, 907-919. ISSN 0959-6526.

Papavasileiou, V. (2015). Sustainable Development and Education: A multidimensional relationship. Athens: Diadrasi. (in Greek)

Papavasileiou, V., Nikolaou, E., Xanthacou, Y. Papadomarkakis, I., Matzanos, D. \& Kaila, M. (2017). Student preschool teachers' views about the pedagogical context of sustainable kindergarten. Proceedings of INTCESS 2017 4th International Conference on Education and Social Sciences. Istanbul, Turkey, 6-8 February, 2017.

Papavasileiou, V., Nikolaou, E., Xanthacou, Y., Xanthis, A., Matzanos, D. \& Kaila, M. (2018). Organization pedagogical use of the spaces in the sustainable kindergarten: views of preschool education graduate students. IJAEDU- International E-Journal of Advances in Education, Vol. IV, Issue 12, 245-250, http://ijaedu.ocerintjournals.org /download/article-file/615354

Pereira, C.G. (2015). Environmental issues and international relations, a new global (dis)order - the role of International Relations in promoting a concerted international system. Revista Brasileira de Política Internacional, On-line version, ISSN 1983-3121.

Platis, M. I. \& Romanowicz, J. (2020). Integrating Energy Saving Awareness into Student EngagementBased Teaching and Learning Process. Sustainability, 12(22), 9626.

Polikovsky, M., Sharon, A. \& Golberg, A. (2018). Enhancing energy literacy in children using zn/cu/potato batteries. F1000Research, 7(24).

Provornaya, I. V., Filimonova, I. V., Eder, L. V., Nemov, V. Y. \& Zemnukhova, E. A.(2020). Formation of energy policy in Europe, taking into account trends in the global market. Energy Reports, 6, 599-603.

Rosidin, U. \& Suyatna, A. (2017). Teachers and Students Knowledge about Global Warming: a Study in Smoke Disaster Area of Indonesia. International Journal of Environmental \& Science Education, 12(4), 777-785.

Tang, S., Wang, Z., Yang, G. \& Tang, W. (2020). What Are the Implications of Globalization on Sustainability? -A Comprehensive Study. Sustainability, 12, 3411. 
Tong, T., Ortiz, J., Xu, C. \& Li, F. (2020). Economic growth, energy consumption, and carbon dioxide emissions in the E7 countries: a bootstrap ARDL bound test. Sustainability and Society, 10, 20.

U.S. Department of Energy. (2019). Energy Literacy: Essential Principles for Energy Education. Office of Energy Efficiency \& Renewable Energy. Accessed 8-12-209 from https://www.energy.gov/eere/education/energy-literacy-essential-principles-energy-education

UNECE. (2019). Mapping of Existing Energy Efficiency Standards and Technologies in Buildings in the UNECE Region. United Nations Economic Commission for Europe. Geneva. Retrieved 18.1.2021 from https://unece.org/fileadmin/DAM/energy/se/pdfs/geee/study/Final Master file March 11 final submission.pdf

van der Horst, D., Harrison, C., Staddon, S. \& Wood, G. (2016). Improving energy literacy through studentledfieldwork - at home. Journal of Geography in Higher Education, 40(1), 67-76.

Yamaguchi, Y., Soki, N. \& Yoshiyuki, S. (2012). Per Capita Energy Consumption for Living, Work, Transport and Other Activities in Cities in the Keihanshin Metropolitan Region, Japan. International Journal of Sustainable Building Technology and Urban Development, 3(1), 68-76.

Yeh, S-C, Huang, J-Y \& Yu, H-C. (2017). Analysis of Energy Literacy and Misconceptions of Junior High Students in Taiwan. Sustainability, 9, 423. 